\title{
Solid-phase (Gelatinized) Storage System of Waxy Crude Oil ${ }^{*}$
}

\section{Introduction}

Some of the high pour-point (H.P.P.) crude oil, such as Daqing (China) and Minas (Indonesia), have a high wax content, and their pour-point is often above $30^{\circ} \mathrm{C}$. Because of these characteristics, H.P.P. crude oil is usually heated to about 50 to $60{ }^{\circ} \mathrm{C}$ to maintain fluidity during storage, at considerable expenses and at some risk to the safety.

To solve those difficulties, Nippon Steel Corporation has developed a new storage system for H.P.P. crude oil, called the solidphase (gelatinized) storage system, in collaboration with Japan National Oil Corporation, a corporation under the control of Agency of National Resources and Energy.

\section{Principle}

The concept of this H.P.P. crude oil storing system is that the oil is received in a tank, left to cool naturally, and is allowed to solidify, or becomes gelatinized, eventually. When it comes to discharge the oil, it is heated to and brought up to the discharging temperature by the top heater suspended from the floating roof, then taken out through a hinged folding pipe (Fig. 1).

\section{Results}

An H.P.P. crude oil (Daqing oil) was received in the demonstration tank, and after the elapse of several months during which the oil became gelatinized, it was discharged with no trouble. This experiment verified high performance and reliability of the oil melting device and high safety of the system, e.g.,

a) Gelatinized oil does not slosh nor spill when hit by earthquake

b) Less corrosion on the tank inner surface

c) No sludge form and deteriora-

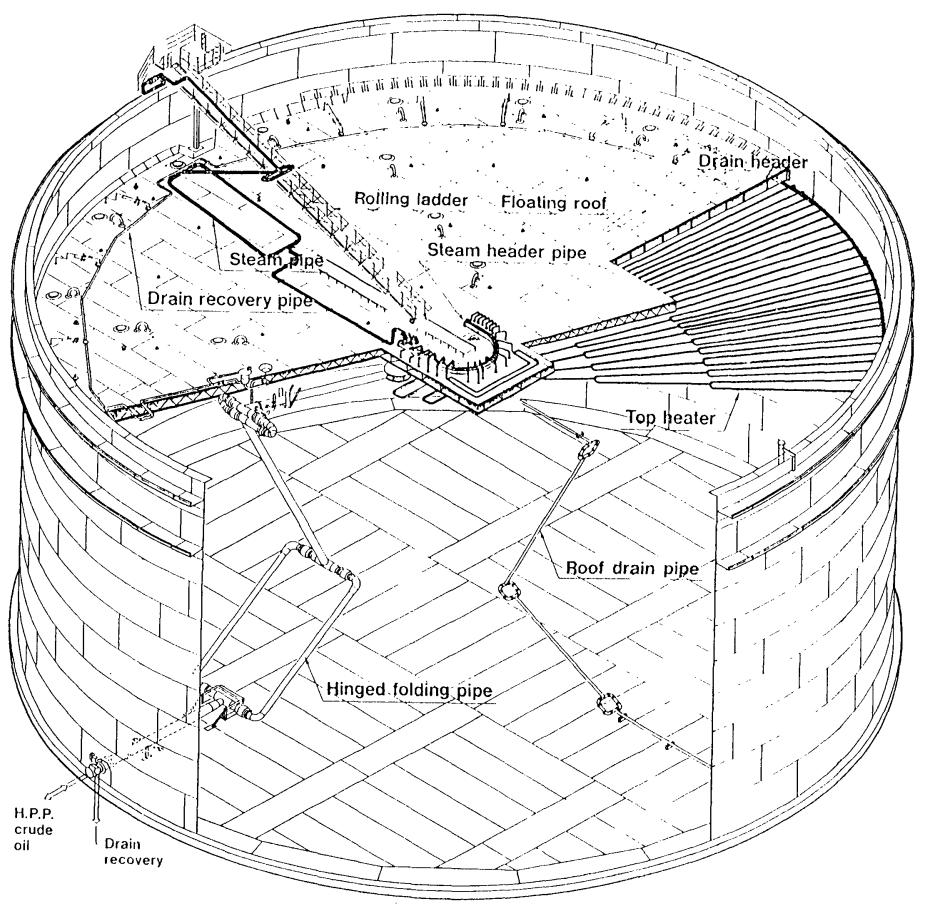

Fig. 1. Design concept (Ground tank). tion of the gelatinized oil

d) Lower vapor pressure of the solidified oil

e) Less steam consumption during oil storing.

Particularly, "Item a)" is described below.

\section{Seismic Behavior}

In the vibration tests using a shaking table, it was found that there was no sloshing of gelatinized H.P.P. crude oil in the tank. Figure 2 shows that the dynamic pressure on the storage tank side wall is lower than when containing liquid oil. Because of these seismic characteristics, it can be said that this system is higher in safety than conventional liquid-phase storage system.

\section{Efflux Behavior}

The H.P.P. crude oil is a Bingham fluid which has an yield stress in the gelatinized state. Therefore, even if a lower part of the tank wall is cracked, the oil will not flow out, provided that the cracks are small or narrow. Even in the worst case, the oil spillage would be limited to very small quantity and area.

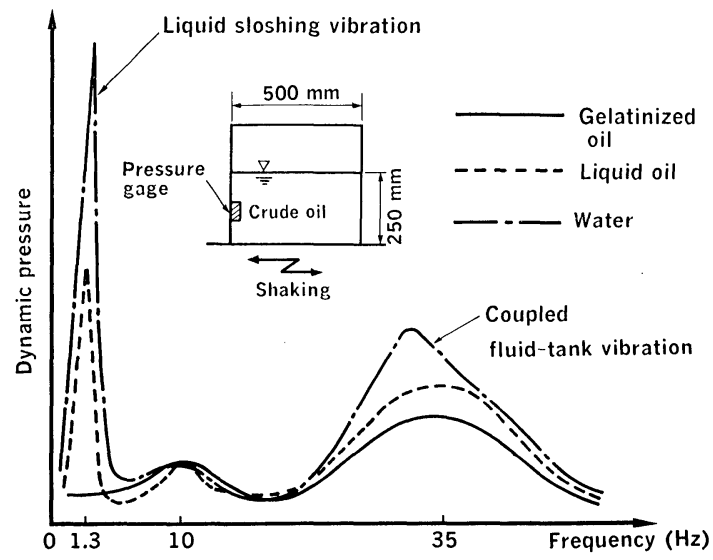

Fig. 2. Comparison of frequency response curve of tank wall to dynamic pressure.

\footnotetext{
* For further information, write to Plant \& Machinery Division, Nippon Steel Corporation, 2-6-3, Otemachi, Chiyoda-ku, Tokyo 100. (C) 1986 ISIJ
} 